Article

\title{
Development and Evaluation of Fall Impact Protection Pads Using Additive Manufacturing
}

\author{
Jung Hyun Park, Hee-Kyeong Jung and Jeong Ran Lee * \\ Department of Clothing and Textiles, Pusan National University, Busan 46241, Korea; \\ jhpark1391@pusan.ac.kr (J.H.P.); jhkfashion@pusan.ac.kr (H.-K.J.) \\ * Correspondence: ljrj@pusan.ac.kr; Tel.: +82-51-510-2841
}

Received: 18 September 2019; Accepted: 18 October 2019; Published: 21 October 2019 updates

\begin{abstract}
This paper presents the development and evaluation of fall-impact protection pants for elderly women using additive manufacturing. The protective pants were designed incorporating a protective pad in the hip area to reduce the impact of falls on the human body. The protective pad is a 3D mesh structure with a curved surface to fit the human body. Pads printed with flexible thermoplastic polyurethane were combined with foam to create the final pad. The impact-absorbing performance of the pad was verified through physical impact experiments. When dropping a bowling ball onto the protective pad from heights of 15,20 , and $25 \mathrm{~cm}$, the protective pad was found to reduce the impact force by more than $82 \%$ in all cases. The impact force was less than the average fracture threshold of $3472 \mathrm{~N}$. A subject group and an expert group evaluated the appearance, pad characteristics, motion functionality, and the wearability of the protection pants. Despite the insertion of a pad, the pants appeared natural and had a good fit. The pads were evaluated as being well-designed in terms of their position, shape, area, thickness, weight, flexibility, ease of insertion, and ease of use. Users were comfortable performing various motions when wearing the designed protective clothing. Therefore, this work can be considered to have developed protective clothing that provides satisfactory impact-protection performance and comfort thereby advancing the possibility of applying additive manufacturing to the creation of functional garments.
\end{abstract}

Keywords: additive manufacturing; protection pad; protective pants; fall-impact protection; design

\section{Introduction}

The additive manufacturing industry has been expanding its scope of application [1], from the manufacturing industry to the biomedical [2-4], agricultural [5], composites [6], aerospace [7,8], and fashion industries $[9,10]$, as a next-generation growth engine that will lead to industrial innovation and creative economy vitalization [11]. The additive manufacturing market is growing explosively because of the development of related technologies and the efforts of companies to innovate and catch up with the rapidly changing tastes of consumers. In the field of fashion, additive manufacturing is mainly used for the development of accessories such as shoes and hats because of relatively easy production $[12,13]$. In the case of apparel and textiles, aesthetic characteristics are usually emphasized although practicality is limited [14,15]. Improving the usability of additive-manufacturing fashion products and utilizing the advantages of the custom-made 3D shapes can expand the additive manufacturing fashion field and contribute to practical use. In medical and virtual garment fields, 3D scanning technology has also been used for capturing patient/customer dimensions [16,17].

The elderly have poorer balance and a lower ability to deal with accidents when compared to those of younger people and, therefore, are easily injured by falls. Older people suffer from greater degrees of injury when they fall, owing to their weak muscles and bones. In addition, the elderly who have experienced falls are not only dependent on others but also suffer from psychological 
difficulties, such as depression and/or loss of confidence [18]. As fractures caused by falls can be physically and psychologically fatal to the health and quality of life of the elderly, it is important to prevent fractures. Hip protectors are effective in reducing the risk of hip fractures by attenuating the impact of a fall $[19,20]$. However, it has been reported that elderly people are reluctant to wear hip protectors because of the inconvenience, difficulty in wearing and removing them, and deterioration of appearance [21,22]. Therefore, it is important to improve the appearance and convenience of use as well as the protective effect, in order to increase the utilization of the hip protector.

So far, most of the experimental studies on hip protectors have been conducted from a biomechanical perspective. In order to verify the effectiveness of the hip protector, experiments using testing simulators were performed under various conditions such as different physical properties, thicknesses, and positions of the pads, different falling angles, and various flooring materials [23-25]. Research on analyzing the impact force through finite-element modeling was also conducted to utilize the information, during the development of hip-protection devices [26,27]. However, it is difficult to find studies that suggest improvements for hip-protection devices, in terms of the wearing characteristics and protective effect. Accordingly, it has become necessary to develop a hip-protection device with high suitability and utilization, which reflects the human body shape.

The purpose of this study was to develop impact-protection pants with curved 3D-mesh pads, using additive manufacturing to verify the impact-protection performance through physical experiments and to evaluate the appearance, pad characteristics, motion functionality, and wearing characteristics of the pants. In this study, the curved 3D mesh pads were designed to develop the impact protection pads with shapes adaptive to the human body surface, and its functionality was verified by presenting the results of the wearing sensory quality evaluation tests. Since there are a limited number of studies on the development of fabric with curved mesh structure, it was necessary to utilize additive manufacturing to overcome such a problem. Additive manufacturing can be applied to develop a protective pad with the desired properties and shapes by adjusting the conditions of detailed additive parameters. Additionally, we used body scan data for the 3D modelling of the pad and which allowed for the design of complex three-dimensional structures reflecting the curved surface of the human body in order to improve the fit and wearing comfort. We targeted for over 60 female subjects to design and develop the pads using the average body scan data of over 60 women. We expected that it was possible to apply the developing processes of this study to other body types, sizes, and ages by utilizing additive manufacturing characteristics for a small quantity of customized productions effectively.

\section{Materials and Methods}

\subsection{Design of Protective Pants}

The pants were designed to reduce the impact of falling by inserting a protective pad in the hip area. In this work, the impact-protection pants were designed to be worn by older women performing daily-life activities and were developed with an emphasis on impact-protection performance, motion functionality, and ease of use.

The impact transmitted in the vertical direction when falling backwards can cause compression fractures in the spine; therefore, it is necessary to protect the bottom of the hip. Hip fractures are caused by impacts to the great trochanter, a bone that protrudes from the upper part of the femur, and most of such fractures require surgery and long hospitalization which increases the risk of death. Therefore, protecting the sides of the hip is also necessary.

In our design, a pocket was made by inserting the designed cutting lines at the edges of the protective part and placing the lining. The design was based on the outer pocket method so that the protective pad could be inserted and removed from the outside easily, even while wearing the pants. The designed cutting lines fixed the pad position while providing an optical illusion wherein the difference in thickness due to the pad insertion was not noticeable. The pants had a slim straight-fit 
silhouette, which is preferred by older women, and an elastic band was inserted into the back of the waist belt to prevent the pants from loosening and to improve the fit (Figure 1).

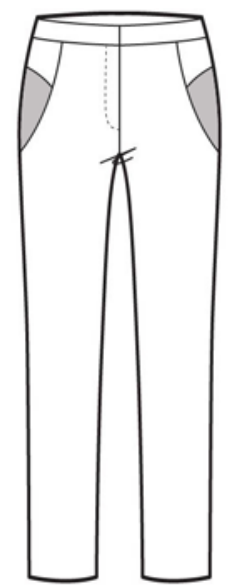

Front

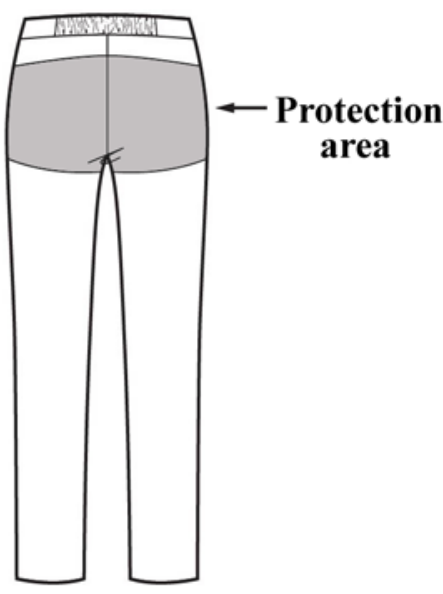

Back

Figure 1. Design of the protective pants. Protection area is shaded.

\subsection{Pattern Design}

The pants' pattern was designed considering the physical characteristics and motion functionality of elderly women. The body measurements for the pattern design were set as follows: waist circumference of $82 \mathrm{~cm}$, hip circumference of $92 \mathrm{~cm}$, hip length of $20 \mathrm{~cm}$, body rise of $26 \mathrm{~cm}$, and pants length of $95 \mathrm{~cm}$, referring to the average size of women, calculated in the 7th South Korea Human Size Survey. The waist belt used an elastic band of length $20 \mathrm{~cm}$ (in total) with $10 \mathrm{~cm}$ on either side of the center back line. As shown in Figure 2, the pattern was cut by drawing a design line on the edge of the protective part and creating a lining pattern. To evaluate the properties of the fabrics, the standard test methods of KS K 0210 (test methods for quantitative analysis of fiber mixtures of textiles), KS K 0514 (measuring method for the weight of cloth), KS K ISO 5084 (measuring method for the weight of cloth), and KS K 0352 (test method for the stretch properties of stretch woven fabrics) were used to determine the fiber content, weight, thickness, and stretch of the fabrics, respectively. As shown in Table 1, the outer material of the pants was a lightweight and stretchable functional fabric and the lining was composed of stretchy and breathable mesh fabric. The pockets were created by placing the lining according to the protection area (Figure 3), and the opening was created by attaching an invisible zipper.

Table 1. Properties of the fabrics used in this study.

\begin{tabular}{cccc}
\hline Properties & Main Fabrics & Lining (mesh) & Test Methods \\
\hline & Polyester $51.1 \%$ & & \\
& $\left(\right.$ Thermolite ${ }^{\circledR}$, Wilmington, DE, USA), & & \\
Fiber content $(\%)$ & Nylon $36.1 \%$ & Polyester $90.5 \%$, & KS K 0210 \\
& $\left(\right.$ Tactel ${ }^{\circledR}$, Wichita, KS, USA), & Polyurethane $9.5 \%$ & \\
Polyurethane 12.8\% & & \\
Weight $\left(\mathrm{g} / \mathrm{m}^{2}\right)$ & $\left(\right.$ Lycra ${ }^{\circledR}$, Wilmington, DE, USA) & 155.1 & KS K 0514 \\
Thickness $(\mathrm{mm})$ & 256.6 & 0.40 & KS K ISO 5084 \\
Stretch $(\%)$ & 1.17 & Wale 83.4 & KS K 0352 \\
& Warp 22.6 & Course 94.5 & \\
\hline
\end{tabular}




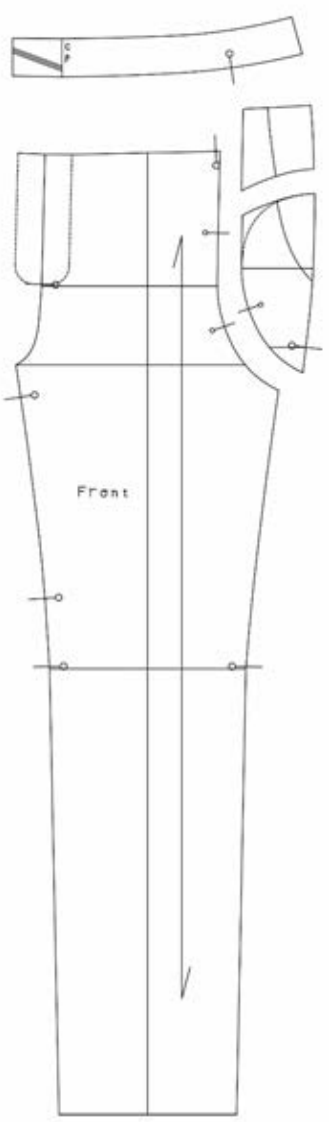

Front

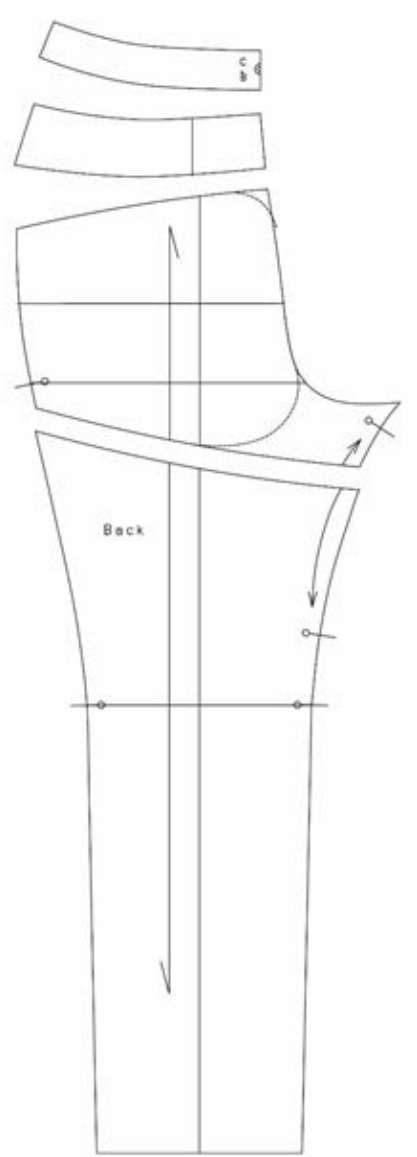

Back

Figure 2. Pattern design for protective pants.
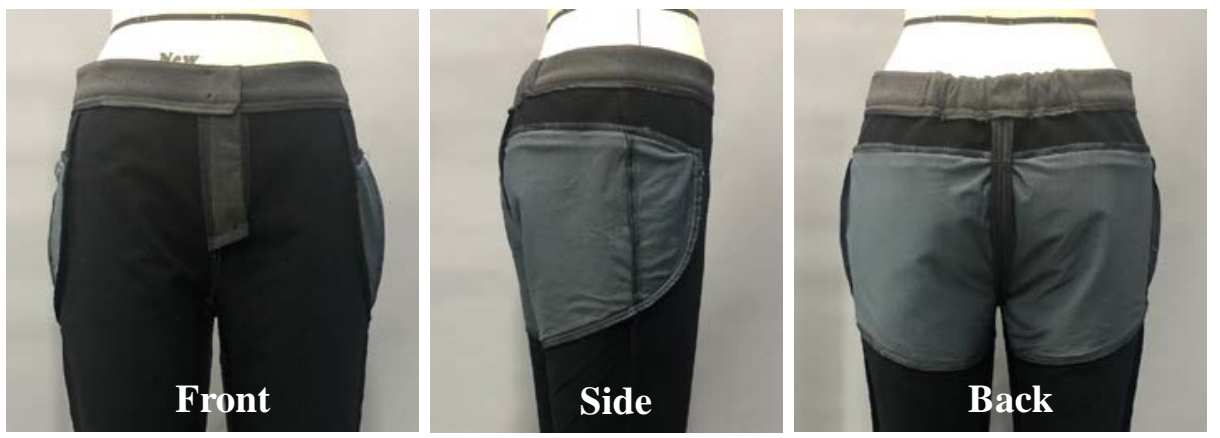

Figure 3. Pocket construction inside the pants.

\subsection{Additive Manufacturing of Pad and Integration}

The protective pad was modeled using the Rhinoceros 5.0 software (Robert McNeel \& Associates, Seattle, WA, USA). The basic unit of the pad was a 3D hexagonal mesh, which had impact-absorbing properties because it was composed of a surface layer (diamond type) and a spacer layer (V-shape). The basic units were connected to each other in a honeycomb shape to form a flexible mesh structure. The mesh structure was deformed according to the body's curvature to improve the fit. As it was difficult to print the entire pad at once, the pad was divided into four pieces, considering the position of the side lines and the shape of the surface (Figure 4). 


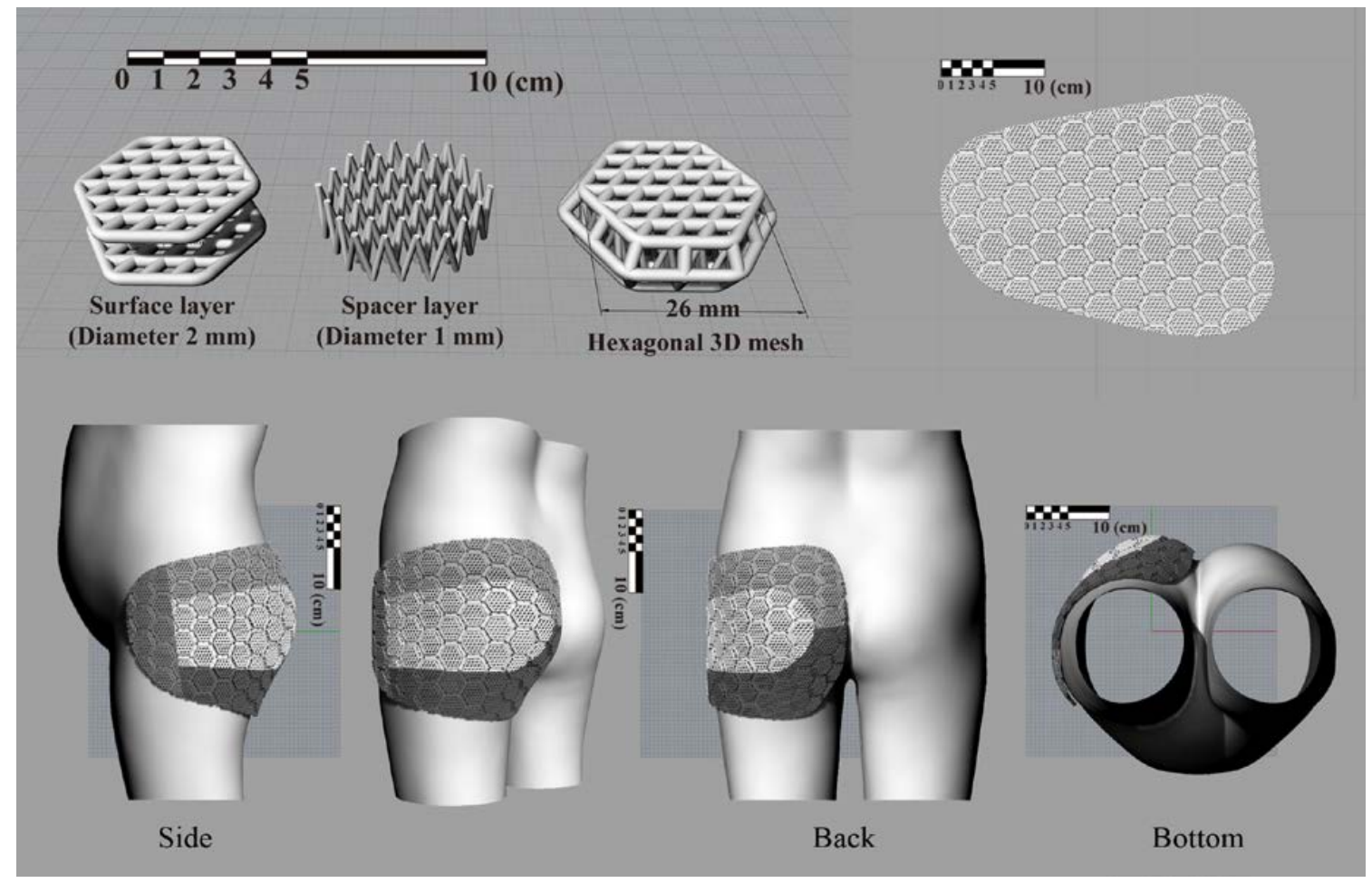

Figure 4. 3D modeling of curved pad.

The 3D model, saved as a stereolithography (STL) file, was converted to a file compatible with 3D printers by generating the G-code using Cubicreator 2.5.2 (CUBICON Inc., Seongnam-si, Korea). The pads were printed at a temperature of $230^{\circ} \mathrm{C}$, using a flexible thermoplastic polyurethane (TPU) filament, NinjaFlex ${ }^{\circledR}$ (NinjaTek, Manheim, PA, USA), by a Cubicon Single 3D printer (CUBICON Inc., Seongnam-si, Korea) based on the fused filament fabrication (FFF) method. Since process parameters have a remarkable effect on the properties of additive manufacturing parts [28], the specifications of TPU filaments and the conditions of additive manufacturing are shown in Tables 2 and 3, respectively. The excellent flexibility of TPU contributes to the easy motion of the pads as well as alleviates the impact from falling. The materials consumption in additive manufacturing is also shown in Table 4 . The material extrusion method was selected due to the fact of its good flexibility and relatively low manufacturing costs. We estimated the cost of printing the pads as USD \$38 in this study.

Table 2. Specifications of thermoplastic polyurethane (TPU) filament.

\begin{tabular}{ccc}
\hline Properties & Value & Test Methods \\
\hline Filament diameter & $1.75 \mathrm{~mm}$ & - \\
Specific gravity & $1.19 \mathrm{~g} / \mathrm{cc}$ & ASTM D792 \\
Tensile strength, yield & $4 \mathrm{Mpa}$ & ASTM D638 \\
Tensile strength, ultimate & $26 \mathrm{Mpa}$ & ASTM D638 \\
Tensile modulus & $12 \mathrm{Mpa}$ & ASTM D638 \\
Elongation at yield & $65 \%$ & ASTM D638 \\
Elongation at break & $660 \%$ & ASTM D638 \\
Hardness & 85 Shore A & ASTM D2240 \\
Glass transition $(\mathrm{Tg})$ & $-35^{\circ} \mathrm{C}$ & DSC \\
Melting point & $216^{\circ} \mathrm{C}$ & DSC \\
\hline
\end{tabular}


Table 3. Conditions of additive manufacturing.

\begin{tabular}{ccc}
\hline Contents & Parameters & Values \\
\hline Material & Flow & $100 \%$ \\
\hline \multirow{3}{*}{ Temperature } & Extruder temperature & $230{ }^{\circ} \mathrm{C}$ \\
& Bed temperature & $40{ }^{\circ} \mathrm{C}$ \\
& Chamber temperature & $40{ }^{\circ} \mathrm{C}$ \\
\hline \multirow{2}{*}{ Quality } & Layer height & $0.2 \mathrm{~mm}$ \\
& Wall thickness & $0.8 \mathrm{~mm}$ \\
& Bottom layer thickness & $0.2 \mathrm{~mm}$ \\
\hline \multirow{3}{*}{ Infill } & Rate & $100 \%$ \\
& Top layer count & $6 \mathrm{each}$ \\
& Bottom layer count & $3 \mathrm{each}$ \\
& Infill overlap & $15 \%$ \\
\hline \multirow{2}{*}{ Speed } & Infill speed & $40 \mathrm{~m} / \mathrm{s}$ \\
& Inner wall speed & $40 \mathrm{~m} / \mathrm{s}$ \\
& Outer wall speed & $30 \mathrm{~m} / \mathrm{s}$ \\
& Bottom layer speed & $20 \mathrm{~m} / \mathrm{s}$ \\
& Travel speed & $100 \mathrm{~m} / \mathrm{s}$ \\
\hline
\end{tabular}

Table 4. Materials consumption of additive manufacturing.

\begin{tabular}{ccc}
\hline Part & $\begin{array}{c}\text { Material Consumption } \\
(\mathbf{m})\end{array}$ & Weight $(\mathbf{g})$ \\
\hline Upper & 34.56 & 103.92 \\
Center & 40.04 & 120.39 \\
Lower & 30.25 & 90.94 \\
Side & 10.44 & 31.39 \\
Total & 115.29 & 346.64 \\
\hline
\end{tabular}

After the supporters were removed from the printed four-piece pads, a $2 \mathrm{~mm}$ thick layer of chloroprene rubber foam (CR foam) was added to the surface that touched the human body, in consideration of wearing comfort, and a $1 \mathrm{~mm}$ thick foam was added to the outer side of the centeral piece for improving the appearance (Figure 5). Properties of CR foam are shown in Table 5. Each component was inserted into a pad case made of stretchable fabric and fixed to function as a single pad (Figure 5), and the connected pad was inserted into a pocket of the pants to be fixed in a protective position.

Table 5. Properties of CR foams.

\begin{tabular}{cccc}
\hline Properties & Foam 1 & Foam 2 & Standard \\
\hline Thickness $(\mathrm{mm})$ & 0.97 & 1.93 & KS K ISO 5084 \\
Hardness & 23 & 25 & ASTM D 2240 \\
Density $\left(\mathrm{g} / \mathrm{cm}^{3}\right)$ & 0.21 & 0.18 & ASTM D 1056 \\
Tensile Strength $(\mathrm{Mpa})$ & 1.3 & 0.8 & ASTM D 1056 \\
Elongation $(\%)$ & 177 & 142 & ASTM D 1056 \\
\hline
\end{tabular}



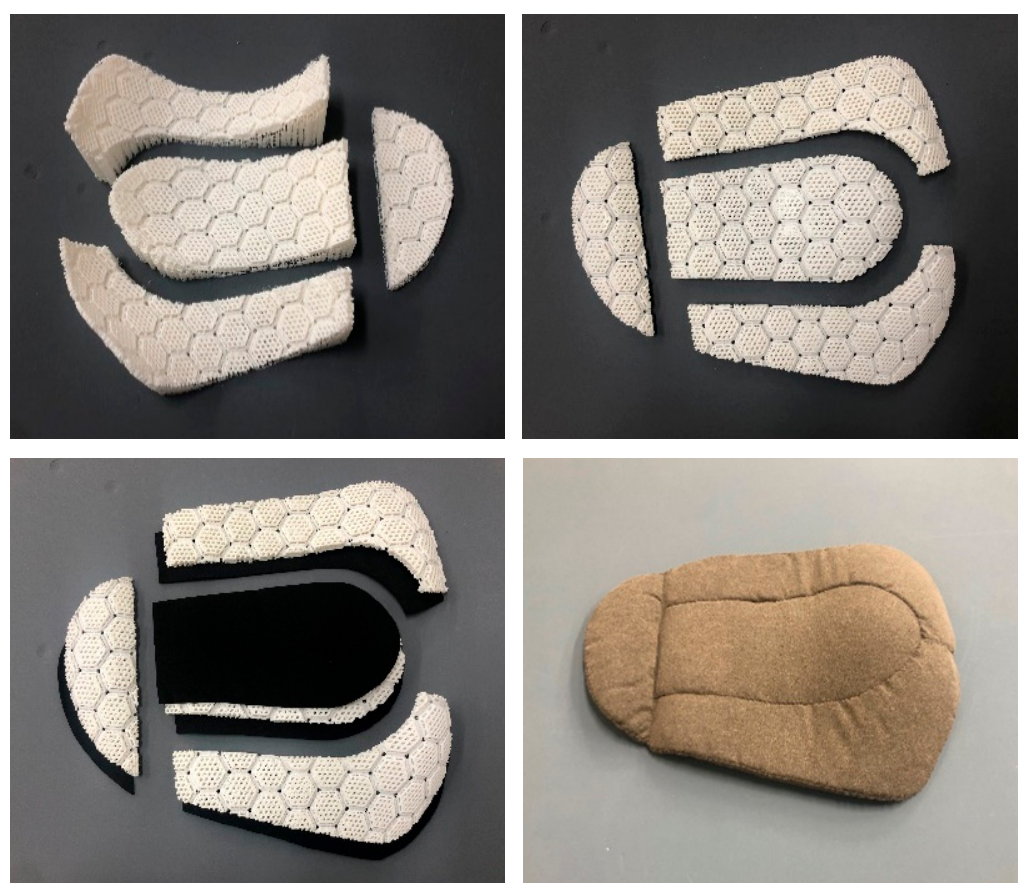

Figure 5. Composition of a 3D-printed curved pad.

\subsection{Evaluation of the Impact-Protection Performance}

To evaluate the impact-protection performance, drop test equipment were arranged as shown in Figure 6. After installing the support on a force plate, a six-pound bowling ball was dropped from various heights on to the protective pad. The impact value generated vertically when falling was measured and compared with the impact value without the pad. The test was repeated 35 times, at heights of 15, 20, and $25 \mathrm{~cm}$. The impact values without pads at heights of 15, 20, and $25 \mathrm{~cm}$ were calculated through extrapolations from force values measured at heights of 6,9 , and $12 \mathrm{~cm}$, because the force plate used in this study was limited to measuring forces above $5500 \mathrm{~N}$. To prevent damages to the sensor and force plate, a $6 \mathrm{~mm}$ thick neoprene fabric was laid on the force plate.

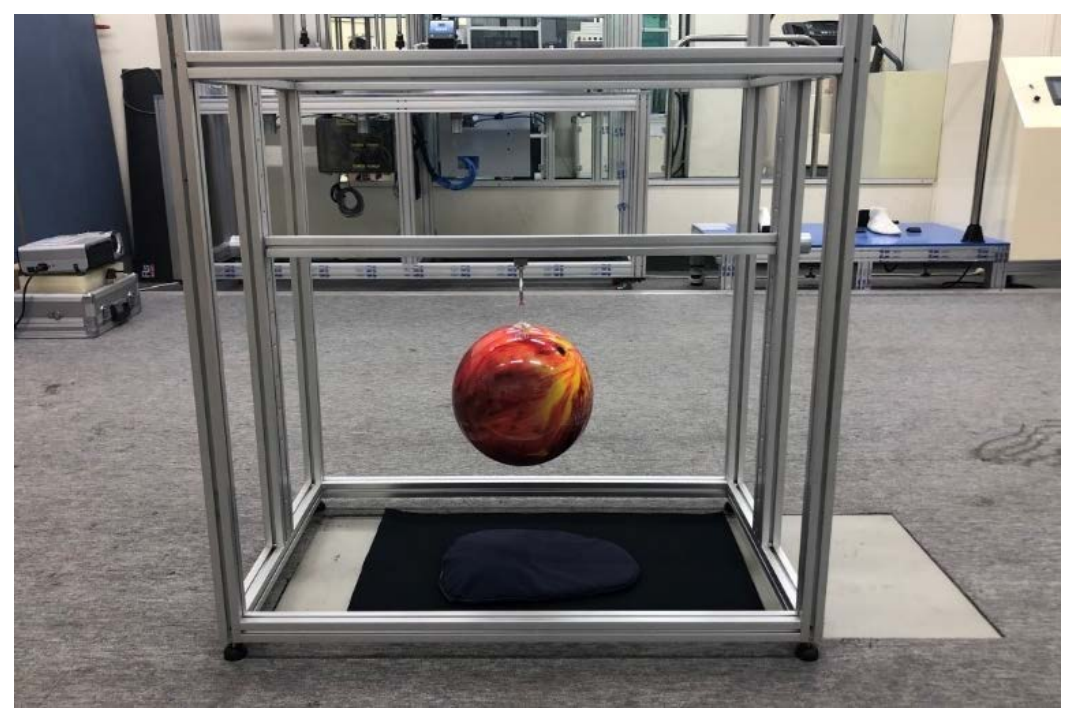

Figure 6. Picture of the impact performance test equipment. 


\subsection{Wearing Evaluation}

The subjects were recruited based on the statistical information of 60 women's body sizes referred by the 7th South Korea Human Size Survey (2015). The number of subjects was 16, including three professional fitting models. The average age of the 16 subjects was $71 \pm 4.63$ years old. The measured body size of the subjects is shown in Table 6 . The wearing evaluation of the impact-protection pants was conducted by a subject group comprising 13 women and an expert group comprising 10 professionals with postgraduate degrees in clothing. The subjects evaluated the appearance of the designed pants by looking in the mirror while wearing the pants. They evaluated their motion functionality after performing six types of movements performed frequently in daily life. The pad characteristics and wearing characteristics were evaluated comprehensively, in terms of practicality, when wearing the pants. The expert group evaluated the appearance by observing the fronts, sides, and backs of three professional fitting models wearing the pants and the pad characteristics by examining the actual pants and manipulating the pads. A 5 point Likert scale, interval scale, was used as the evaluation scale for all parameters, where " 1 point" meant "strongly disagree" and " 5 points" meant "strongly agree". Descriptive statistics were used to evaluate the sensory quality of the appearance, pad characteristics, motion functionality, and wearing characteristics. The Mann-Whitney $U$ test was performed to compare the results on the appearance evaluation and pad characteristics between subjects and the expert group.

Table 6. Body size of the subjects.

\begin{tabular}{ccccc}
\hline \multirow{2}{*}{ Contents } & \multicolumn{2}{c}{ Subjects $(\mathbf{n}=\mathbf{1 6})$} & 60 Women (The 7th South Korea Human Size Survey) \\
\cline { 2 - 5 } & Mean & SD $^{\mathbf{1}}$ & Mean & SD $^{\mathbf{1})}$ \\
\hline Waist circumference $(\mathrm{cm})$ & 81.1 & 2.81 & 86.0 & 7.91 \\
Hip circumference $(\mathrm{cm})$ & 93.0 & 2.61 & 92.6 & 5.13 \\
Height $(\mathrm{cm})$ & 154.9 & 2.18 & 152.9 & 4.78 \\
Weight $(\mathrm{kg})$ & 54.8 & 3.20 & 59.0 & 7.61 \\
\hline \multicolumn{5}{c}{ 1) Standard deviation. }
\end{tabular}

\section{Results and Discussion}

\subsection{Evaluation of the Impact-Protection Performance}

When a force of approximately $6500 \mathrm{~N}$ was applied to the pad from a height of $15 \mathrm{~cm}$, an impact value of $1005 \pm 16 \mathrm{~N}$ was obtained with the protective pad indicating a decrease of $84.5 \%$. When a force of approximately $8000 \mathrm{~N}$ was generated from a height of $20 \mathrm{~cm}$, an impact value of $1312 \pm 35 \mathrm{~N}$ was observed with the protective pad representing an impact reduction of $83.6 \%$. When approximately $9500 \mathrm{~N}$ was applied from a height of $25 \mathrm{~cm}$, an impact value of $1723 \pm 61 \mathrm{~N}$ was obtained with the protective pad, and a decrease of $81.9 \%$ was achieved, as shown in Figure 7. In general, the maximum impact value on the pelvis during a fall is known to be approximately $8000 \mathrm{~N}$. The impact-protection pants used in this study were capable of reducing the impact to below the average fracture threshold of $3472 \mathrm{~N}$.

Percentage force attenuation (\%) was calculated to obtain the impact reduction performance of the curved three-dimensional mesh protection pad using Equation (1).

$$
\text { Percentage Force Attenuation }(\%)=\left(1-\frac{F_{T}}{F_{0}}\right) \times 100
$$

where $F_{T}$ is the impact force $(\mathrm{N})$ using the protection pad and $F_{0}$ is the impact force $(\mathrm{N})$ without the protection pad, respectively. We achieved a percentage force attenuation (\%) of $83.6 \%$ with the drop height of $15 \mathrm{~cm}$. As shown in Figure 8, Schoor et al. [25] reported the percentage force attenuations (\%) with a range of $18.7-46.5 \%$ using commercially available soft hip protectors, such as polyurethane- 
and polystyrene elastomer-based hip protectors. Commercially available soft hip protector pads were tested by applying the force of $6378 \pm 141 \mathrm{~N}$ using a drop impact test with a substitute pelvis and 0.5 inch thick soft tissue. Thus, the results of the percentage force attenuation indicated that the curved three-dimensional mesh protection pad provided excellent impact protection performance.

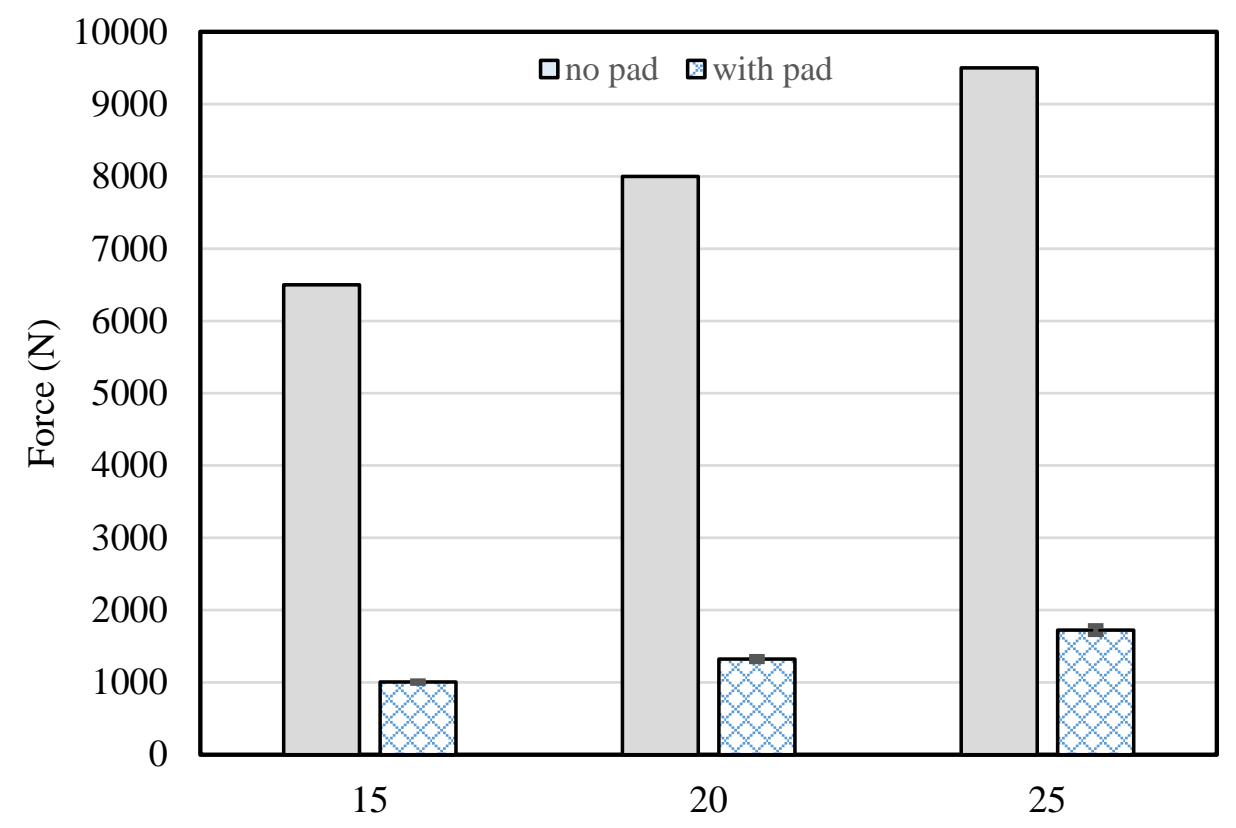

Figure 7. Impact-protection performance test without pad and with pad, in the cases of application of forces generated at heights of 15,20 , and $25 \mathrm{~cm}$.

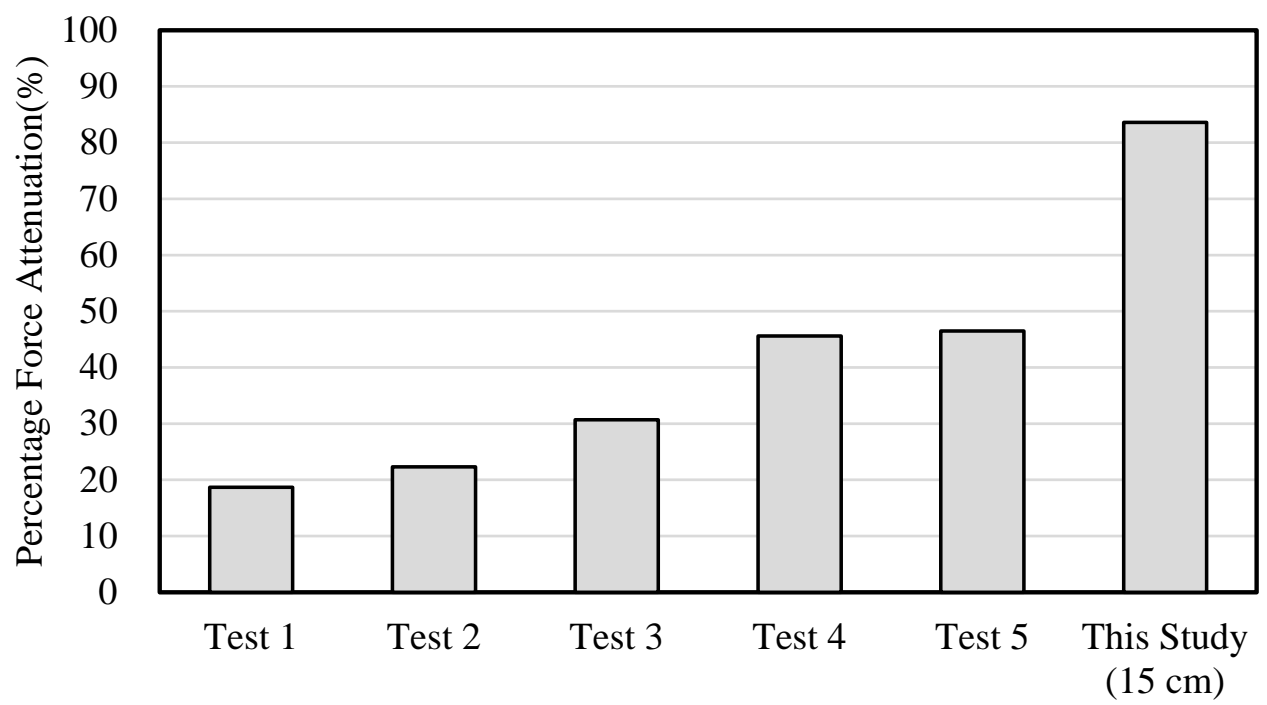

Figure 8. Percentage force attenuations. Tests 1, 2, 3, 4, and 5 were conducted with Safety Pants (Raunomo Oy, Tampere, Finland), Gerihip (Pervent Products, Inc., Rochester, MN, USA), Lyds Hip Protector (Lyds International BV, Velsen-Noord, The Netherlands), HipSaver (HipSaver, Inc., Norwood, MA, USA), and Safety Pants (Van Heek Medical, Venray, The Netherlands), respectively [25].

\subsection{Evaluation of Appearance}

For parameters related to the appearance evaluation (Figure 9 and Table 7), the subject group awarded 4.69 points or higher and the expert group awarded 4.00 points or higher. Both the subjects 
and experts were satisfied with the color and material of the pants because dark gray, which was preferred by the elderly women, was selected and a material with good elasticity and functionality was used. The design line at the part where the pad was inserted was identified properly, in consideration of the protective parts, and even though a $13 \mathrm{~mm}$ thick pad was inserted, the part where the pad was inserted looked natural. Because of the proper consideration given to the stretch of fabric and the pad thickness, the fit at the waist circumference and hip circumference was good, without wrinkles/tugging at the crotch area.

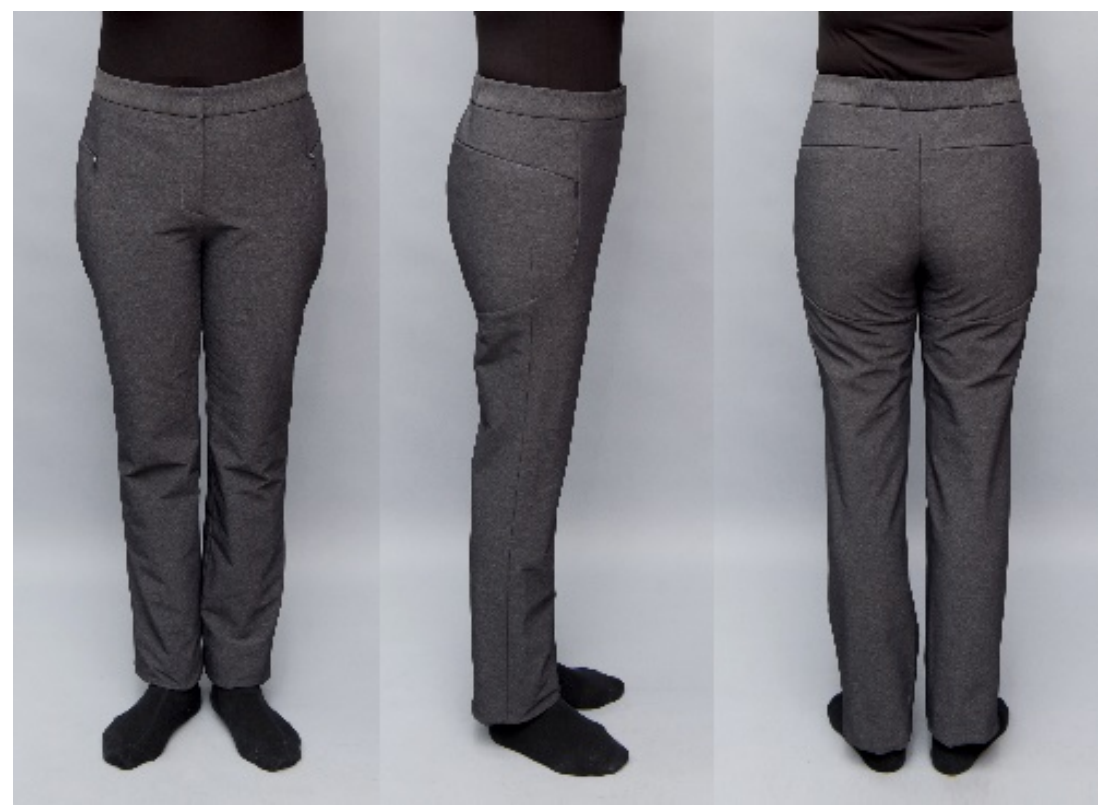

Figure 9. Appearance of the designed pants.

Table 7. Results of appearance evaluation.

\begin{tabular}{cccc}
\hline \multicolumn{1}{c}{ Contents } & $\begin{array}{c}\text { Subjects } \\
(\boldsymbol{n = 1 3 )}\end{array}$ & $\begin{array}{c}\text { Experts } \\
(\boldsymbol{n}=\mathbf{3 0})\end{array}$ & $\boldsymbol{p}$-Value \\
\cline { 2 - 3 } & Mean (SD) & Mean (SD) & \\
\hline Is the color of the pants good? & $5.00(0.00)$ & $4.40(0.70)$ & 0.009 \\
Is the fabric of the pants good? & $4.92(0.28)$ & $4.60(0.52)$ & 0.099 \\
Is the fit of the pants good? & $5.00(0.00)$ & $4.13(0.82)$ & 0.001 \\
\hline Is the design line at the part where the pad is inserted good? & $4.92(0.28)$ & $4.27(0.79)$ & 0.014 \\
Does the area where the pad is inserted look natural? & $4.69(0.48)$ & $4.00(1.08)$ & 0.083 \\
Is the location of the waistline suitable? & $4.92(0.28)$ & $4.57(0.73)$ & 0.184 \\
Is the waist circumference suitable? & $4.77(0.60)$ & $4.50(0.68)$ & 0.243 \\
Is the hip circumference suitable? & $5.00(0.00)$ & $4.30(0.88)$ & 0.009 \\
Does the crotch area appear good, without & $4.85(0.38)$ & $4.07(0.87)$ & 0.006 \\
Is the length of the pants suitable? & $4.85(0.38)$ & $4.10(1.16)$ & 0.070 \\
\hline
\end{tabular}

The Mann-Whitney's U-test was performed to compare the appearance evaluation between subjects and the expert group. As shown in Table 7 , there were differences $(p<0.05)$ in the appearance evaluation for color, fit, design line, hip circumference, and crotch area contents between subjects and the expert group. The difference of fit content was especially significant between subjects and the expert group, because the expert group evaluated the appearance by observing the subject models, while the subject group responded to the question while wearing the pants. Therefore, we assumed that the subject group showed better satisfaction on the fit evaluation than the expert group. 


\subsection{Evaluation of Pad Characteristics}

The pad characteristics were evaluated in terms of their position, form, area, thickness, weight, flexibility, insertion method, and ease of use. As shown in Table 8, a high score of four or more was awarded for the shape, area, and position of the pad, because the pad was designed to cover the hips and pelvis, considering appearance and protection. In the expert evaluation, a score of 3.90 was awarded for the thickness of the pad, which was slightly lower than the scores for other parameters. However, in the subject evaluation, a score of 4.69 was awarded, indicating that the thickness of the pad was sufficiently comfortable during actual wearing. The weight of the pad was awarded 4.00 points or higher in both the subject and expert evaluations, confirming that the pads were designed to be within the range of weight that could be worn reasonably. Thickening the intensive protection area and thinning toward the edges reduced the inconvenience caused by the thickness and weight of the pad. The flexibility of the pads showed good results because the pads were designed to be flexible in terms of the structure and were printed using a flexible TPU. The subject group gave a perfect score or near-perfect score for the pad insertion method and ease of manipulation, and the expert group gave a good score of 4.50 or higher. This may be because the pocket is fixed securely and the pads can be inserted and removed easily from the outside opening, as shown in Figure 10.

Table 8. Results of the evaluation of pad characteristics.

\begin{tabular}{cccc}
\hline \multirow{2}{*}{ Contents } & Subjects $(\boldsymbol{n}=\mathbf{1 3})$ & Experts $(\boldsymbol{n = 1 0 )}$ & \multirow{2}{*}{$\boldsymbol{p}$-Value } \\
\cline { 2 - 3 } & Mean $\left(\mathbf{S D}^{\mathbf{1})}\right)$ & Mean (SD $\left.{ }^{\mathbf{1})}\right)$ & \\
\hline Is the location of the pad appropriate? & $4.92(0.28)$ & $4.60(0.70)$ & 0.243 \\
Is the shape of the pad appropriate? & $4.85(0.38)$ & $4.40(0.84)$ & 0.159 \\
Is the area of the pad appropriate? & $4.62(0.51)$ & $4.40(0.97)$ & 0.784 \\
Is the thickness of the pad appropriate? & $4.69(0.48)$ & $3.90(0.88)$ & 0.004 \\
Is the pad light? & $4.38(0.65)$ & $4.00(0.47)$ & 0.074 \\
Is the pad flexible? & $4.77(0.60)$ & $4.30(0.68)$ & 0.032 \\
Is the pad insertion method appropriate? & $5.00(0.00)$ & $4.50(0.71)$ & 0.039 \\
Is it easy to insert and remove the pads? & $4.92(0.28)$ & $4.70(0.48)$ & 0.254 \\
\hline
\end{tabular}

1) Standard deviation.
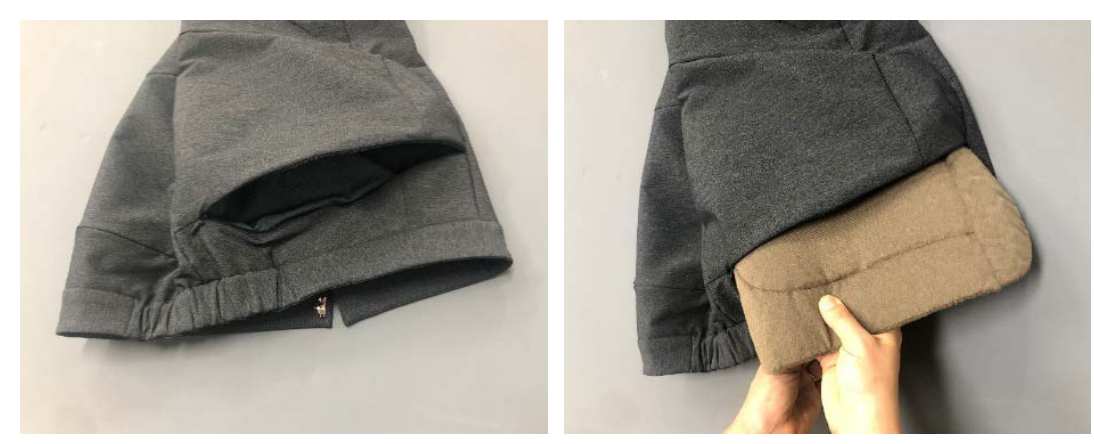

Figure 10. Insertion and removal of pad.

The Mann-Whitney's U-test was performed to compare the evaluation of pad characteristics between subjects and the expert group. As shown in Table 8 , there were differences $(p<0.05)$ in thickness, flexibility, and pad insertion method contents. Since the average scores from the subject group were higher in the evaluation of pad characteristic for thickness, flexibility, and pad insertion method contents than the expert group, the experts tended to give a slightly lower score than the subject group. 


\subsection{Evaluation of Motion Functionality}

The subject group evaluated the motion functionality after performing various movements while wearing the protective clothing. As shown in Table 9, all parameters scored 4.69 or higher. Therefore, even when wearing protective clothing with a pad, there was no inconvenience in movement. In particular, the subjects did not feel uncomfortable when sitting on a chair or bending their upper body. The pad was designed to fit the curved surfaces of the human body and had flexibility, which contributed to good motion functionality. We calculated the Cronbach's alpha for determining the reliability among the contents. The Cronbach's alpha is a measure of internal consistency, that is, how closely related a set of items are as a group. We obtained the Cronbach's alpha of 0.62 indicating acceptable reliability of contents in the evaluation of motion functionality.

Table 9. Results of the evaluation of motion functionality $(n=13)$.

\begin{tabular}{ccc}
\hline Contents & Mean & SD \\
\hline Are you comfortable when sitting in a chair? & 4.92 & 0.28 \\
Are you comfortable when squatting? & 4.69 & 0.48 \\
Is it comfortable to bend the upper body forward (90 degrees)? & 5.00 & 0.00 \\
Is it comfortable to bend your knees (90 degrees)? & 4.62 & 0.51 \\
Are you comfortable when walking? & 4.77 & 0.44 \\
Are you comfortable when going up and down the stairs? & 4.77 & 0.44 \\
Is it comfortable to make body motions, in general? & 4.85 & 0.38 \\
Cronbach's alpha & & 0.62 \\
\hline
\end{tabular}

\subsection{Evaluation of Wearing Characteristics}

As shown in Table 10, a score of 4.77 or higher was rated for all aspects of the wearing characteristics for the pants. The stretch and feel of the pants were good, indicating that the choice of fabric was appropriate. It was convenient to put on and take off the pants even when the protective pads were inserted. No discomfort or pressure was felt at the sites where the impact-protection pads were inserted and, therefore, the design and insertion of the pads were deemed appropriate, considering the characteristics of the human body. We obtained the Cronbach's alpha of 0.61 indicating acceptable reliability of the contents in the evaluation of wearing characteristics.

Table 10. Results of the evaluation of wearing characteristics $(n=13)$.

\begin{tabular}{ccc}
\hline Item & Mean & SD \\
\hline Is the feel of the pants good (outside)? & 4.92 & 0.28 \\
Is the feel of the pants good (inside)? & 4.85 & 0.38 \\
Is the stretch of the pants good? & 4.85 & 0.38 \\
Is it convenient to put on and take off the pants? & 4.85 & 0.38 \\
Is there any discomfort or pressure at the areas & 4.77 & 0.44 \\
where the pads are inserted? & & 0.61 \\
Cronbach's alpha & & \\
\hline
\end{tabular}

Standard deviation.

\section{Conclusions}

In this study, additive manufacturing was used to fabricate pads that fit human body shapes, and the fabricated pads were integrated into impact-protection pants. The curved 3D-mesh pads were designed for developing the impact protection pads with shapes adaptive to the human body's surface, and its functionality was verified by presenting the results of the wearing sensory quality evaluation tests. We also used the body scan data for 3D modeling of the pads which allowed for the design of complex three-dimensional structures reflecting the curved surface of the human body 
in order to improve the fit and wearing comfort. A physical impact evaluation was performed on the developed protective clothing to verify the impact-absorption performance objectively. A subject group and an expert group evaluated the appearance, pad characteristics, motion functionality, and wearing characteristics of the protective clothing thereby verifying the practical use of the garment. The developed impact-protection pants were found to be suitable for the body shapes of elderly women and could be worn for a long time while performing daily-life activities. The protective pads reduced the impact by more than $82 \%$ and can help prevent hip fractures in the case of falls. This study confirmed the basis for the fabrication of new pads, which are unlike the existing fall-impact protection pads that use foam materials, using additive manufacturing. This study contributes to improving the quality of life for the elderly through the development of fall-impact protection clothing and can be extended to develop various types of protective clothing. In the near future, we plan to investigate the design and characteristics of a bridge connecting the hexagonal structure of pads for developing superior motion adaptable fall-impact protector using additive manufacturing.

Author Contributions: J.H.P. and H.-K.J. performed the experiments; J.R.L. conceived the research idea; J.H.P. and J.R.L. wrote the main manuscript text.

Funding: This research was supported by the Basic Science Research Program through the National Research Foundation of Korea (NRF) funded by the Ministry of Education (2015R1D1A1A09057667 and 2019R1A6A3A01096512).

Conflicts of Interest: The authors declare no conflict of interest.

\section{References}

1. Ngo, T.D.; Kashani, A.; Imbalzano, G.; Nguyen, K.T.; Hui, D. Additive manufacturing (3D printing): A review of materials, methods, applications and challenges. Compos. Part B Eng. 2018, 143, 172-196. [CrossRef]

2. Rengier, F.; Mehndiratta, A.; Von Tengg-Kobligk, H.; Zechmann, C.M.; Unterhinninghofen, R.; Kauczor, H.-U.; Giesel, F.L. 3D printing based on imaging data: review of medical applications. Int. J. Comput. Assist. Radiol. Surg. 2010, 5, 335-341. [CrossRef] [PubMed]

3. Yang, T.Y.; Lin, S.W.; Xie, Q.G.; Ouyang, W.W.; Tan, T.B.; Li, J.H.; Chen, Z.Y.; Yang, J.L.; Wu, H.Y.; Pan, J.; et al. Impact of 3D printing technology on the comprehension of surgical liver anatomy. Surg. Endosc. 2019, 33, 411-417. [CrossRef] [PubMed]

4. Vithani, K.; Goyanes, A.; Jannin, V.; Basit, A.W.; Gaisford, S.; Boyd, B.J. An Overview of 3D Printing Technologies for Soft Materials and Potential Opportunities for Lipid-based Drug Delivery Systems. Pharm. Res. Dordr. 2019, 36, 4. [CrossRef] [PubMed]

5. Tanase-Opedal, M.; Espinosa, E.; Rodríguez, A.; Chinga-Carrasco, G. Lignin: A Biopolymer from Forestry Biomass for Biocomposites and 3D Printing. Materials 2019, 12, 3006. [CrossRef]

6. Adumitroaie, A.; Antonov, F.; Khaziev, A.; Azarov, A.; Golubev, M.; Vasiliev, V.V. Novel Continuous Fiber Bi-Matrix Composite 3-D Printing Technology. Materials 2019, 12, 3011. [CrossRef]

7. Joshi, S.C.; Sheikh, A.A. 3D printing in aerospace and its long-term sustainability. Virtual Phys. Prototyp. 2015, 10, 175-185. [CrossRef]

8. Hehr, A.; Wenning, J.; Norfolk, M.; Sheridan, J.; Newman, J.A.; Domack, M. Selective Reinforcement of Aerospace Structures Using Ultrasonic Additive Manufacturing. J. Mater. Eng. Perform. 2019, 28, 633-640. [CrossRef]

9. Vanderploeg, A.; Lee, S.-E.; Mamp, M. The application of 3D printing technology in the fashion industry. Int. J. Fashion Des. Technol. Educ. 2017, 10, 170-179. [CrossRef]

10. Perry, A. 3D-printed apparel and 3D-printer: Exploring advantages, concerns, and purchases. Int. J. Fashion Des. Technol. Educ. 2018, 11, 95-103. [CrossRef]

11. Gebler, M.; Uiterkamp, A.J.S.; Visser, C. A global sustainability perspective on 3D printing technologies. Energy Policy 2014, 74, 158-167. [CrossRef]

12. Yap, Y.; Yeong, W. Additive manufacture of fashion and jewellery products: a mini review: This paper provides an insight into the future of 3D printing industries for fashion and jewellery products. Virtual Phys. Prototyp. 2014, 9, 195-201. [CrossRef] 
13. Pasricha, A.; Greeninger, R. Exploration of 3D printing to create zero-waste sustainable fashion notions and jewelry. Fashion Textiles 2018, 5, 30. [CrossRef]

14. Pei, E.; Shen, J.; Watling, J. Direct 3D printing of polymers onto textiles: experimental studies and applications. Rapid Prototyp. J. 2015, 21, 556-571. [CrossRef]

15. Melnikova, R.; Ehrmann, A.; Finsterbusch, K. 3D printing of textile-based structures by Fused Deposition Modelling (FDM) with different polymer materials. In IOP Conference Series: Materials Science and Engineering; IOP Publishing: Bristol, UK, 2014; p. 012018.

16. Magnenat-Thalmann, N.; Kevelham, B.; Volino, P.; Kasap, M.; Lyard, E. 3D Web-Based Virtual Try On of Physically Simulated Clothes. Comput. Aided Des. Appl. 2013, 8, 163-174. [CrossRef]

17. Makitie, A.A.; Salmi, M.; Lindford, A.; Tuomi, J.; Lassus, P. Three-dimensional printing for restoration of the donor face: A new digital technique tested and used in the first facial allotransplantation patient in Finland. J. Plast Reconstr. Aes. 2016, 69, 1648-1652. [CrossRef]

18. Gallagher, B.; Corbett, E.; Freeman, L.; Riddoch-Kennedy, A.; Miller, S.; Smith, C.; Radensky, L.; Zarrow, A. A fall prevention program for the home environment. Home Care Provid. 2001, 6, 157-163. [CrossRef]

19. Laing, A.; Robinovitch, S. Effect of soft shell hip protectors on pressure distribution to the hip during sideways falls. Osteoporos. Int. 2008, 19, 1067-1075. [CrossRef]

20. Choi, W.; Hoffer, J.; Robinovitch, S. Effect of hip protectors, falling angle and body mass index on pressure distribution over the hip during simulated falls. Clin. Biomech. 2010, 25, 63-69. [CrossRef]

21. Minns, R.; Marsh, A.M.; Chuck, A.; Todd, J. Are hip protectors correctly positioned in use? Age Ageing 2007, 36, 140-144. [CrossRef]

22. O'Halloran, P.D.; Murray, L.J.; Cran, G.W.; Dunlop, L.; Kernohan, G.; Beringer, T.R. The effect of type of hip protector and resident characteristics on adherence to use of hip protectors in nursing and residential homes-An exploratory study. Int. J. Nurs. Stud. 2005, 42, 387-397. [CrossRef] [PubMed]

23. Li, N.; Tsushima, E.; Tsushima, H. Comparison of impact force attenuation by various combinations of hip protector and flooring material using a simplified fall-impact simulation device. J. Biomech. 2013, 46, 1140-1146. [CrossRef] [PubMed]

24. Laing, A.C.; Feldman, F.; Jalili, M.; Tsai, C.M.J.; Robinovitch, S.N. The effects of pad geometry and material properties on the biomechanical effectiveness of 26 commercially available hip protectors. J. Biomech. 2011, 44, 2627-2635. [CrossRef] [PubMed]

25. Van Schoor, N.M.; Van Veen, A.J.; Schaap, L.A.; Smit, T.H.; Lips, P. Biomechanical comparison of hard and soft hip protectors, and the influence of soft tissue. Bone 2006, 39, 401-407. [CrossRef] [PubMed]

26. Daners, M.S.; Wullschleger, L.; Derler, S.; Schmitt, K.-U. Development of a new design of hip protectors using finite element analysis and mechanical tests. Med. Eng. Phys. 2008, 30, 1186-1192. [CrossRef]

27. Majumder, S.; Roychowdhury, A.; Pal, S. Effects of trochanteric soft tissue thickness and hip impact velocity on hip fracture in sideways fall through 3D finite element simulations. J. Biomech. 2008, 41, 2834-2842. [CrossRef]

28. Salmi, M.; Ituarte, I.F.; Chekurov, S.; Huotilaine, E. Effect of build orientation in 3D printing production for material extrusion, material jetting, binder jetting, sheet object lamination, vat photopolymerisation, and powder bed fusion. Int. J. Collab. Enterp. 2016, 5, 218-231. [CrossRef]

(C) 2019 by the authors. Licensee MDPI, Basel, Switzerland. This article is an open access article distributed under the terms and conditions of the Creative Commons Attribution (CC BY) license (http://creativecommons.org/licenses/by/4.0/). 